\title{
Interview with Heather Love
}

\section{So ‘90s?}

In some places people are trying to write their dissertations on queer topics and are encountering opposition because what they are doing seems unprecedented, a break with academic norms. Their advisors just say, "No, no one has ever done that before and you can't either." But elsewhere, it seems like queer topics are already passé. I heard of someone who was told, "You can't write a queer dissertation - that's so '90s."

Some people assume the good old days of queer theory have passed because they think of extremely brilliant, prominent, individual thinkers, such as Judith Butler, Eve Kosofsky Sedgwick, D. A. Miller, and so on. Where is the Judith Butler of today? This is part of the reason why I have been drawn to work on queer method. For me, method is about teaching and about the idea that rather than queer theory being the writings of a few individual geniuses, it should be something that can be and should be taught, and that anyone can do. I think it is okay to make clear what we think the field of queer studies is, and teach it widely. Even if it is not always the most brilliant, exceptional work, that is okay with me. People say, "Oh the work now, it's boring, it just copies other people." But copying other people - we also call that learning. If the field is to grow it has to include all kinds of scholarship, original, unoriginal, brilliant, dutiful, etc. I want many, many people to know how to think about sexuality, say in literature, without having to make it up themselves, or have to be a genius. We want some of those mind-blowing books that completely change everything, of course, but we also want regular books.

I am on the side of institutionalization. Queer Studies is an odd field because in a way it became prominent and prestigious, but certain kinds of institutionalization never happened. There are many universities where Queer Studies is not taught at all, or the people who teach it are precarious and overloaded with work. So it's been important to me to build the field's capacity and infrastructure. We are still missing a lot. At the same time the field is facing a crisis of a different kind. As LGBT people have become more integrated into public life in the US, the outsider stance of queer thought and activism has run up against its limits. In particular, it remains difficult to address the sea change caused by the legalization of same-sex marriage.

A friend of mine said to me, "You know, at the moment when queer theory emerged, in the late ' $80 \mathrm{~s}$, it really expressed a great popular movement and a popular anger, primarily around HIV/AIDS. That was the match that lit the keg." Many of the key theoretical insights of queer theory - ideas that we now see as highly abstract or arcane - came directly out of activist struggle and real-world necessity. Now, we have a bit of a problem. Queer theory emerges from a conflict between assimilation and resistance - to norms, to the couple, to rights-based politics, even to capitalism and the family. But 
now, there is a truly mass movement for integration, whether we like it or not. That movement has achieved significant gains, which we could not have and did not imagine in the 1980s. If many of us still feel the need to oppose these things, we must recognize that we are doing so in opposition to a huge part of the community. I think our politics are in greater conflict than ever with the feelings and the reality of LGBT people. We need to think about how to have queer theory keep its critical and radical edge, but still be in contact or in communication with broad-based movements.

\section{Activism and Academia}

I was dismayed when the fight for gay marriage took center stage in the movement, because I have misgivings about marriage both as a feminist and as a queer person. I do not think that queer theory needs to line up with mainstream movements, and just get behind gay marriage, but I think we need to find other ways of articulating our critiques. If we hold out utterly against social changes that are taking place, we risk becoming less and less relevant. The concept of homonormativity has gained a lot of traction in recent years, and it describes something real and recognizable. But it is often used in terms that are too sweeping, suggesting consistent and irreversible gains for LGBT people as well as the possibility, for some, of living outside social norms. As we know, recent political gains, though real, are fragile and uneven, and norms are called norms because they affect everyone in some measure.

The landscape has really changed - legally, culturally, in terms of media presence and representation. However, it is still a relatively small slice of LGBT people who can expect this kind of representation and protection, or who stand to gain from it. For non-white and poor queers, for gender-nonconforming queers, for the undocumented and the disabled and the unhoused, life looks really different. I am from Kentucky and I am very aware that the shiny image of the lives of LGBTQ people that you sometimes get is not true. OK, there are LGBT celebrities who are like the Greek gods. They have lives like no one else. Even we, academics, are definitely in a bubble. If you had told me 20 years ago that I would be paid to talk and think about queer issues, it would be like a strange dream that I could not have imagined when I was growing up. So I have struggled a lot to think about how much my perspective is colored by my own situation. I am interested in figuring out how to be critical without being condescending. Not only is this an important personal ethics, it is also a way of being strategic, because it is perfectly clear to people when they are being condescended to, and it is not the way to build an inclusive movement. I do think the lessons of queer theory, even in its most critical and transformative aspects, can be part of that, but the "anti-" in antinormativity is not helping.

I think a lot through the politics of location, which is why I remain so focused on questioning the perspective of academics. Despite significant overlaps, it is hard to ignore the tensions between queer activism and queer academia. At the famously contentious Gay Shame conference in 2003, one of the big fights was caused by tensions between academics investigating shame and the activists they invited to participate. They had invited an anti-gentrification, anti-capitalist, anti-mainstream activist group called Gay Shame San Francisco. The activists turned up, but they were not happy, partly, I 
think, because they felt the organizers had gained intellectual capital from choosing the group's name as the title of their conference without crediting them. But also, I think, they felt alienated from many of the discussions on what shame means, on the political potential of stigma and other conceptual questions. When I saw the fights and interactions, I realized that was basically a class conflict. People who are marginally employed and in quite precarious situations do not want to hear those well-paid academics with job security talking about shame. I have had such a class transition in my own life, so I am very attentive to class issues. I think this is part of the challenge that we face, trying to think through such issues, forge links with anti-capitalist movements, but also just address economics at all. Paying attention to social class and political economy has been a weakness of US queer theory, which tends to focus on culture instead.

\section{Thinking Transnationally}

Increasingly the field [of Queer Studies] has tried to expand and to think transnationally. But part of the problem with doing transnational work in the US is that Queer Studies shares the structure of US cultural imperialism, so it takes categories that were developed in the US, and imposes them on other locations.

One of the first questions I ask when I travel is about the words people use. What is the history of those words? How does queer theory signify in this context? Because vocabulary is such a powerful thing. The students [at the Queer Studies 2 conference in Warsaw] were saying they were so impressed that the transformation of "queer" from a negative to a positive term had been successful. They said, "I don't think that's ever really happened in Polish. I can't think of a term that started as a slur and was then transformed into a positive term." The word "feminist," they explained, had gone through different phases, of being at first used as an insult and then reclaimed, but its history was different. "Queer" would be one of the most obvious examples of a term which circulates globally and which can do important work, but there is a lot of mistranslation and tension, and it can't even be pronounced in some languages.

\section{Histories}

Many questions [about the applicability of queer theory] come out of particular local histories, but I have had some moments of surprising connection. For instance, in 2010 I spent about ten days in Taiwan, where I gave a series of lectures and met with an amazing community of activists and academics. They were very interested in the history of conflicts in feminism and the sex wars in the US, because, they said, they had gone through their own sex wars around SM and pornography after martial law was ended in 1987. And they were fascinated by the work of Gayle Rubin, which spoke so much to their context. Although I am never surprised by the influence of Rubin's work, still, these are connections you would not necessarily expect. 
[At the Warsaw conference] students said, "We understand how this worked in the US: first there was feminism and gay liberation, followed by conflicts in feminism and changes in the LGBT community, and queer came after that." Whereas in Poland, they said, everything came at once: feminism, gender studies, gay and lesbian studies, and queer studies all came in one package and are developing at the same time. Now it is certainly true that there is no necessary order to the development of gender and sexuality studies. It was basically a historical accident how these things developed in the US, and it is not necessary to go through those stages, one after the other. But that historical sequence has been incorporated into narratives of queer theory written in the US, and is an important part of how I teach the field and think about it in my own scholarship. So the translation that needs to happen as the field continues to expand is quite significant-it is not only a matter of terms and categories, but also the complex struggles that gave rise to them.

Since I was trained as a modernist, I tend to think about Baudelaire's definition of modernism: on the one hand, as a historical period, and on the other, as a tendency toward the new. Do we think about queer as a part of history, as something that has happened and is still happening, or do we think about it as a tendency or force that is ahistorical. The work I am doing now is trying to historicize the term queer, but there is something within queer that resists that kind of historicization.

I often go back into that moment in "Critically Queer" where Judith Butler states: If "queer" is going to continue to do political work, and that's an open question for her, then it will do so because it continues to draw energy from the history of injury that it cites. For her "queer" is about taking the history of damage and turning it to good political uses. That would be very close to my definition of queer; that's what compels me about it. And then she says, "queer" may not be the word that will do the work forever; something else might have to replace it. We have to keep asking ourselves: Is this word, or this field, doing the work it needs to?

The field has never lacked internal or immanent critiques. For instance, Tim Dean published a scathing review of Lee Edelman's conversation with Lauren Berlant in Sex, or the Unbearable, saying: "Where is the sex, guys? Why does sex remain as such a missing object?" That critique comes back again and again. I am guilty as charged, having written on affect, friendship, intimacy, temporality - anything but sex. Though I've never focused on sex per se, I do think about it, naturally. But seriously, I think a robust engagement with sex as a practice is essential to queer thought, and my own thinking about sexual community and affect really depends on people's willingness to go there.

\section{Maturity and Age}

I have a critique of maturity as a normative form. Some of the most compelling artwork and aesthetics in queer culture have to do with the refusal to grow up. I think of the works of the filmmaker Sadie Benning, which were literally made with a toy camera in her bedroom when she was 15 . For many people it's their favorite queer video work. Benning uses handwritten signs that she films, and one of the signs that she flashes says: "Tomboy forever." This conveys the idea that you can stay in a 
moment that was supposed to be just a stage, that lasted for a year or two and was an awkward time to be outlived. That such a moment could become an adult identity - I think that's an important idea, one that challenges widespread notions about what it means to be a responsible citizen or a proper member of society. I relate to this idea viscerally through my gender identity, since I tend to like wearing the same clothes as a teenage boy. That tomboy label is interesting because it is both about gender and age.

There is of course a long tradition of dismissing homosexuality as a failure to develop or maturethink of Freud on "arrested development." That is about getting stuck in a stage of infancy, whereas the danger zone for me is more around twelve. But I think the pathology is a bit overblown. I love how some styles of queerness or gay culture transformed oppression into positive modes of being. Nothing reveals the incredible creativity of subculture more than this. I think the embrace of immaturity is a powerful response to being told that you are a tragic case of arrested development, while at the same time not being allowed to achieve certain landmarks of adulthood - to get married or have children, do the kind of things that signal you're an adult. To not be crushed by that doublebind but to use it create a new aesthetic, or culture, new forms of relation - that to me is the most beautiful thing about queer culture. And though I am eager to throw off historical forms of oppresssion as much as anyone, I do fear that this aspect of queer culture will get lost in the shuffle. Gay people can have access to marriage and family, which is great, but on what terms? What Sadie Benning created, then, becomes just a pathological or a bad way of living, whereas to me that was a beautiful form of life. People are just leaving that behind, because the whole community has to grow up now and meet these marks of adulthood. I feel very ambivalent about that.

But on a more personal note, as much as I am attracted by the teenager forever idea, maturity has always had its own draw and reality for me. Even as a kid, I felt old, and all through my 30s, I shared a joke with my friends that we were "Old Granddads," just old guys sitting around on the porch and whittling sticks. Now that I am actually old, or getting there, I feel mentally prepared for it, even though what I think I often related to in the past was maturity out of sequence, premature maturity. One more piece of this is that I was born in 1970. My parents were young when they had me, and they were living the hippie life, lots of freedom and partying. I did drugs with my parents when I was a little kid, and it wasn't always in super safe situations. So when I became a parent, I realized that safety was important to me, it was always something I had wanted. I think being unsafe is fine, important even, but that deciding these questions for your kids is not ok. We tend to think queer culture invented certain kinds of experiments-arounds drugs, or sex, or ways of living collectively. But of course there was no single norm, ever, and the queer movement came out of a rich brew of feminism and socialism and sexual liberation and a whole slew of other social changes. And as queer culture has moved closer to the mainstream, the necessary relation between same-sex love and resistance to norms has become harder to maintain, even as an ideal.

As for my own way of living out these issues, you could just say I had kids and then I became more conservative-oldest story in the book. But actually I was parenting my younger brother and sister 
when I was a kid, and I always felt like I had to be the mature one-more than the adults who were around me. So I've always had a kind of identification with maturity, one that was not really optional for me-or never felt that way. Families are complex things, and it is a real shorthand to say that queer people don't have access to families. Some of the work on queer kinship has tried to speak back to this simplification. But it is also another lesson-as if we needed more-in how looking at queerness along, without addressing gender, race, and class, misses so much.

\section{Institutions (Marriage and Academia)}

There is both a queer and a feminist rationale for the critique of marriage. We can talk about the way that the institution has been exclusive (clearly!) and oppressive to women (also clearly!). But I also think more generally this form has tended to shut down on the kinds of care and generosity that can happen outside of the couple or the family. I think about queer networks of care, enduring friendships, surprisingly resilient forms of connection, and the entire social world as a potential realm for care-taking, and attention. These visions of collective life may seem impossibly distant, but I think we practice forms of care outside of our immediate circle all the time. In a way, teaching has been that for me. But also non-biological forms of parenting. I've written a bit about The Argonauts by Maggie Nelson, in which she discusses queer and feminist parenting. She writes that in the feminist world there's always been kids around. Women have kids, and people just figure out how to take care of them. That is really an ideal for me.

I do think of teaching as one of these ideal forms of non-biological relation, but it takes place within an institution that is not ideal in many ways. But institutions do now seem more important than ever, because of the way that they provide sources of support for things besides commerce. Also, while institutionalization has been widely critiqued in queer studies, and in other political fields, I think we don't have to think about it as a top-down operation. It can also be the kind of networks that we can build within the institution, through queer virtualities or horizontal connections. I've now had 15 years of relationships with students whom I mentor and teach. When I say I'm for institutionalization, what I mean is that I would like those people to have jobs, I would like them to be able to continue be scholars and do their work, so I will do everything I can to make that happen. You can be against institutionalization, but that is what is at stake, pragmatically - the fostering of sustainable spaces of thought and creativity for people younger than me. Academia has been a real force for good in my life. It has created opportunities for me that I could never have had otherwise, and I want to pass those on. How can we bring this ethics of care into an institutional context? There are real challenges in US academia, which is increasingly class-stratified and closed to so many. There are still incredible opportunities for learning and growth and change, but these opportunities are increasingly closed to those who cannot afford them-a larger and larger share of the world's population. In my vision of teaching as a kind of care outside of familial networks, it is important that the closed system of the family is not simply replaced by a closed system of wealth and privilege. I am obviously implicated 
in these transformations as well, and so far I haven't seen my way to do much more than acknowledge that fact, rather than try to obscure it—while I may be politically Left, my implicit countenancing of the defunding of public education is a real problem.

I wrote my first book Feeling Backward from the position of an outsider, from my experience of growing up in the American South, without money, in a very difficult family situation, with a lot of violence, and my gender. These are some of the reasons why I felt like I don't identify with the center in many ways. And I was very vested in trying to express what I thought was a kind of politics coming out of that marginal location. The work I am doing now, for instance, on Erving Goffman and knowledge production, is about trying to grapple with actually having institutional authority. It's important not to disavow that and say, "I'm a queer radical, because those are my politics," and yet I have so much more social recognition, and a sort of footing in the social world that I didn't have before, so I'm trying to do work that grapples with the ethics of that. That's one of the unexpected consequences of pursuing this career: if you keep at it, even as an outsider, you can eventually end up an insider.

\section{Affects and Action}

I can't believe there is this thing called affect studies, because it just fits so much with my personality or what I think is important in the world, or the kind of communities that I have been in. Because I was trained as a literature professor, I don't really do affect theory. I don't theorize affect, in a senseinstead, I just try to carefully describe emotions, something that I think novels do really well.

Talk about a field where the history of institutionalization has been interesting, and taken some unexpected turns. I have been teaching in the field of affect studies for the past two decades, and watching it develop. There is a pretty significant split, right down the middle of the field. On the one side, there is a Deleuzian approach to affect theory - non-psychological, maybe not representational even. On the other side, there is a cultural studies approach. I'm very much in the cultural studies camp, coming out of Raymond Williams and British cultural studies, as well as Eve Sedgwick's work with Silvan Tomkins. Since I was originally trained in psychoanalysis, French feminism, semiotics, and deconstruction, for me the shift away from psychoanalysis (of course I am still interested in psychoanalysis, but I work now much more in affect studies) is part of the shift to a descriptive vocabulary. I take inspiration from Sedgwick's interest in Tomkins's work and even Proust's fiction as a descriptive taxonomic project. She says at one point that Proust is trying to describe every kind of person there is in the world, and I appreciate this kind of flexibility and additive quality of those systems of affect in which it is treated as an activity, something that you do rather than something that is. That has been very productive for me. It was useful in thinking about different qualities of queer historical experience that might not fit into existing categories. I think it's related to the work on description I am doing now, which focuses less on the structural topography of the mind, and more on affect and 
interaction as a pragmatic affair, a happening. So maybe I don't have a lot of perspective on its limits, but I certainly see that my own take on it is fairly situated in the Anglo-American psychological tradition-that tradition clearly has limits, geographical ones to begin with.

For others, affect theory might be much more productive. But I deeply feel - here's my own affect coming out! - that thinking about emotion, about feeling, is very important for both diagnosing social situations and developing political strategy. Scholars in affect studies - the sort of BerlantCvetkovich version of affect studies - talks about taking the temperature of the body politic to find out what is going on. Cognitive categories, conceptual categories, often are not enough. How do we get a sense of what the collective mood is? For instance, Jonathan Flatley has been very interested in mood. Once you have a way of thinking more clearly about experiences that can be overwhelming or confusing or fuzzy, or simply part of an unnoticed background, then you have a better sense of how to intervene, or how to move forward.

I think affect is what glues people together, what binds people together, what motivates them to act: these are all question about affect for me. Understanding what the situation is and having a critical view of it is important, but it's not enough. This is the critique of the Left that's been going on for some years now. Sedgwick talks about it as the politics of exposure: just show people what's wrong and then they'll say, "Oh, right." It's obviously not adequate to the rise of nationalism, and people voting against their interests, as they do. But again, I think there is the longer history of political thinking about affect which has been very condescending, for instance, towards the crowd or fascism. From this perspective, the masses are irrational. I'm trying to think with popular sentiment, not against it, not to just give into it but to have some relation to it. It seems to me that without that effort, you can be "correct," but your ideas will not get any traction or have any utility.

The interview was conducted by Tomasz Sikora in Kraków on June 7, 2016. It was edited and authorized for publication in December 2020. 